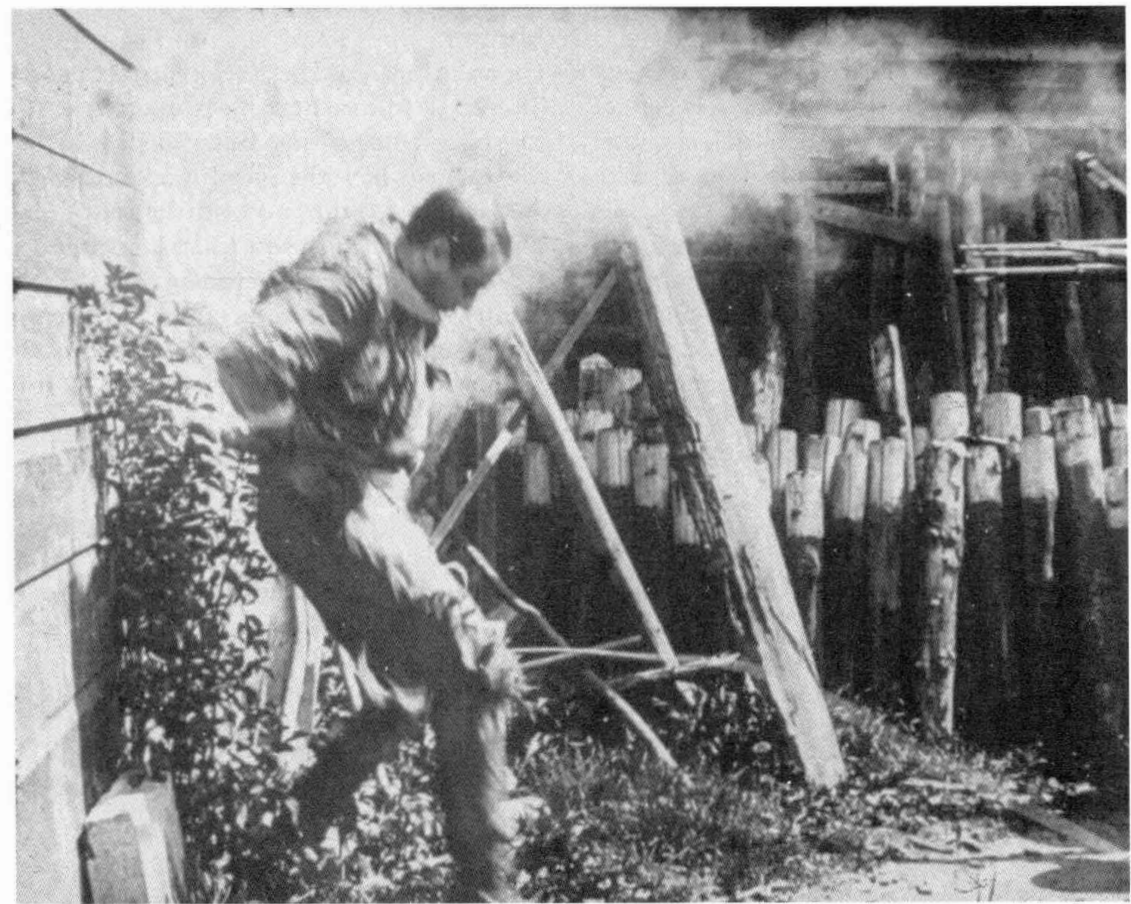




\section{María Dolores Lorenzo}

Licenciada en Historia por la Universidad Iberoamericana de México y obtuvo el grado de maestría por la Universidad Nacional Autónoma de México y por El Colegio de México. Actualmente, es aspirante al doctorado en Historia de El Colegio de México con el tema de la "asistencia pública durante el porfiriato". En otros trabajos ha estudiado diversos aspectos relativos a la inmigración española a finales del siglo XIX y principios del Xx.

\section{Resumen}

El artículo analiza el desarrollo del Banco Oriental de México desde la perspectiva de la política laboral. En un enfoque "desde abajo", el trabajo destaca cómo los mecanismos sociales de la comunidad hispánica en el sur oriente de México contribuyeron para que la instirución mercantil se convirtiera en uno de los principales bancos de emisión del país. Los aspectos relevantes del artículo se refieren, en cuanto al tema, al estudio de los empleados bancarios y, respecto de las fuentes, a la revisión sistemática de los libros de actas del Consejo de Administración del Oriental.

\section{Palabras clave:}

Bancos, inscituciones mercantiles, empleados, españoles, política laboral, Puebla, Oaxaca, Chiapas.

\section{Abstract}

The article analyzes the development of Banco Oriental de México from the perspective of labor policy. Using a "from below" approach, the study shows how the social mechanisms of the Hispanic community in the southeast of Mexico enabled this mercantile institution to become one of the main issuing banks in the country. The article focuses on the bank's employees, on the basis of a systemaric review of the minute book of Banco Oriental's Board of Directors.

\section{Key words:}

Banks, mercantile institutions, employees, Spaniards, labor policy, Puebla, Oaxaca, Chiapas.

Fecha de recepción:

marzo de 2005

Fecha de aceptación: junio de 2005 


\title{
"Ayúdame que yo te ayudaré". La política laboral en el Banco Oriental de México (1900-1915)
}

\author{
Maria Dolores Lorenzo
}

$\mathrm{D}$ urante los últimos años del porfiriato y los primeros de la revolución, un grupo de industriales y comerciantes españoles establecidos en Puebla fundaron diversas instituciones que realizaron operaciones bancarias en ese estado y en Oaxaca, Chiapas, Tlaxcala y Veracruz, así como en la ciudad de México. Este grupo de peninsulares, encabezado por Manuel Rivero Collada, dirigió sus negocios financieros a través del Banco Oriental de México, que se convirtió en el principal banco local de emisión del país, después de recibir en 1904 un importante aumento de capital, proporcionado por el Banco Hispano Americano de Madrid. " Además de su participación en los negocios bancarios, los promotores del Oriental eran propietarios de importantes industrias textiles, haciendas cerealeras, plantas de blanqueo e ingenios azucareros, entre otras actividades emprendidas, sobre todo, en el estado de Puebla. ${ }^{2}$ Así, estos empresarios españoles conjuntaron capi-

1. Archivo General de la Nación (en adelante AGN), Antiguos Bancos de Emisión, Banco Oriental de México, Libro de actas, 1.22 .2 , acta núm. 133,9 de febrero de 1903, p. 77v; acta núm. 182, 27 de diciembre de 1903, p. $136 \mathrm{v}$ y acta núm. 184,4 de enero de 1904, p. 139.

${ }^{2} \mathrm{La}$ incursión en diversas actividades, entre las cuales destaca el negocio financiero, fue una caracte- tales de orígenes diversos para explotar la concesión de la emisión de billetes entre otros servicios financieros. ${ }^{3}$

En esta investigación comenzaré por examinar someramente los mecanismos que coadyuvaron a la expansión de esta empresa bancaria en la región sur oriental del país, y expondré, de manera general, cómo los promotores del Banco Oriental utilizaron la legislación en beneficio de la empresa y en qué sentido estos empresarios aprovecharon los mercados locales, nacionales e internacionales para diversificar sus operaciones e impulsar el negocio financiero. Si bien reconocemos que el marco institucional y la habilidad de los banqueros para aprovechar coyunturas específicas trazaron las pautas del crecimiento de la empresa, en este trabajo me inte-

rística del grupo dominante de la industria textil en Puebla. Gamboa, Empresarios, 1985, p. 202.

${ }^{3}$ Respecto a la relación entre banca e industria en el proceso del desarrollo capitalista: Hilferding, $\mathrm{Ca}$ pital, 1971, y Cameron, Historia, 1998. Para el contexto español, Tortella, Desarrollo, 1998. Para el caso mexicano, cabe resaltar los trabajos de Carlos Marichal, Leonor Ludlow y Leticia Gamboa como precursores del análisis de la estructura social del crédito, la banca y la industria en México durante el siglo XIX y principios del xx. Gamboa, Empresarios, 1985; Ludlow y Marichal, Banca, 1985, Cerutri y Marichal, Banca, 2003. 
resa, sobre todo, subrayar algunos aspectos relativos a la política laboral como factores que, también, contribuyeron al desarrollo del Oriental y a la modernización de la banca comercial del porfiriato. Así, analizaré, de manera específica, los mecanismos del reclutamiento del personal, la distribución de los salarios, la movilidad de puestos y la terminación de las relaciones laborales en la institución, como aspectos de la administración interna que favorecieron la expansión de ese Banco del porfiriato.

Considerando que los empleados del Oriental pertenecían a la comunidad de españoles establecidos en México, e incluso que algunos dependientes estaban relacionados con los directivos de la empresa por lazos de parentesco, mostraré que los vínculos familiares y de paisanaje fueron decisivos en la conformación de la planta de empleados del Banco; asimismo, expondré que los promotores del Oriental estructuraron una política laboral que sistematizó las relaciones de parentesco y paisanaje, lo cual contribuyó a la eficiencia operativa requerida para la expansión del negocio financiero en un periodo de transformaciones significativas en el ámbito empresarial. ${ }^{4}$

${ }^{4}$ Alfred D. Chandler, precursor de la historia de las empresas, centró su análisis en el desarrollo del "capitalismo gerencial" estadunidense y propuso que la empresa moderna, administrada por așalariados, sustituyera a la pequeña empresa familiar como instrumento para dirigir la producción. Según Chandler, esta "mano visible de la dirección" confirió un carácter decisivo para la transformación, crecimiento y predominio de la empresa moderna en Estados Unidos. Chandler, Mano, 1987, p. 15. En los últimos años, otros estudios plantean la necesidad de precisar, según los contextos específicos, de qué manera las formas organizarivas constituyeron un elemento indispensable en la conformación y desarrollo de la empresa moder-
La historia de los bancos ha dirigido su atención, principalmente, al origen del capital, a las características sociales de los accionistas y a la actividad empresarial de los promotores de los bancos, como factores que explican el tránsito hacia la empresa moderna. En este afán, algunos altos directivos también han sido objeto de otros estudios. ${ }^{5}$ Pero los dependientes del Banco, sobre los cuales recaía el funcionamiento cotidiano de la empresa, son un grupo que aún no ha recibido la debida atención entre los historiadores. " De tal manera, esta investigación incursiona en un campo hasta ahora nada explorado: el de los empleados bancarios. Es cierto que estos trabajadores "de cuello blanco" no pertenecían a los grupos más bajos de la sociedad, sino que se insertaban en un rango medio; por lo tanto, decir que éste es un enfoque "desde abajo" parecería exagerado. Sin embargo, mi intención consiste en restituir una historia que se ha dejado de lado y que podría darse por perdida, si olvidáramos que el desempeño de los empleados de los bancos contribuyó activamente en la expansión de los negocios

na. Para el caso de los bancos en España, García, Remesas, 1992, y García, "Internal", 2000. Respecto del tránsito de la empresa moderna en el contexto de la banca en México, Marichal, "Banca", 1999.

${ }^{5}$ Una minuciosa exposición de la historiografía sobre la banca en México es el artículo de Carlos Marichal y Gustavo A. del Ángel. Ángel y Marichal, "Poder", 2003.

${ }^{6}$ A partir de la propuesta de Youseff Cassis la historiografía sobre la banca ha prestado mayor atención a los directivos y gerentes. No obstante, la historiografía sobre los empleados bancarios aún es escasa. Algunos trabajos representativos y que se refieren a esta ausencia son Hill, Subservice, 1982; Cassis, City, 1994; Núñez, "Banco", 1985, pp. 209-225, y García, "Internal", 2000. 
financieros en México, todo lo cual merece ser recuperado para adquirir la visibilidad que estos empleados tuvieron al participar, día con día, en aspectos decisivos del desarrollo bancario del país. ${ }^{7}$

\section{LOS MECANISMOS INSTITUCIONALES DE LA EXPANSIÓN BANCARIA}

El contexto legal bancario imperante en México durante el porfiriato definió las características específicas de la estructura de los bancos en el país. ${ }^{8}$ Un aspecto decisivo fue que la Ley de Instituciones de Crédito de 1897 uniformó las condiciones legales para la competencia bancaria. ${ }^{9}$ Asimismo, esta legislación proporcionó ciertas ventajas que se reflejaron en la proliferación de concesiones bancarias, otorgadas inmediatamente después de su publicación. ${ }^{10}$ Empero, la ley de 1897 no supuso la desaparición de casas y empresas de particulares que realizaban operaciones financieras, aunque carecieran de una concesión gubernamental. Por consiguiente, a partir de 1897, el contexto legal en mate-

${ }^{7}$ Sharp, "Historia”, 1993, pp. 56-57.

${ }^{8}$ Cameron, Historia, 1998, p. 356.

${ }^{9}$ Como consecuencia de la publicación de la Ley de Instituciones de Crédito, el Banco Nacional de México renunció, entre otros beneficios que le otorgaba su contrato de concesión, al privilegio que le aseguraba la negativa de las autoridades para autorizar otras concesiones que explotaran el negocio bancario. Memoria, 1900, pp. 32-59, y Ludlow y Salmerón, Emision, 1997, p. 201.

${ }^{10}$ Barrera, Estudios, 1909 , p. 115 . Mónica Gómez expone que los factores de carácter institucional y económico fueron los que determinaron, al menos parcialmente, los rasgos sobresalientes del crecimiento de la banca de emisión en México. Gómez, "Crecimiento", 2003, pp. 321-345. ria bancaria confirió un carácter mixto al sistema financiero mexicano. En este sistema, conocido por los contemporáneos como "monopolio plural", coexistieron bancos que tenían un otorgamiento gubernamental y empresas dedicadas al negocio bancario que operaban sin concesión y por ello estaban reguladas por el Código de Comercio de 1884 . $^{11}$

Los promotores del Banco aprovecharon la coyuntura legal para estructurar un sistema bancario compuesto por tres instituciones: el Banco Oriental de México, el Descuento Español y el Español Refaccionario. El primero obtuvo la concesión para funcionar como banco de emisión de Puebla en 1899; los dos últimos se constituyeron como sociedades anónimas en 1904 y 1911 , respectivamente. También los bancos de emisión de los estados de Oaxaca y Chiapas conformaron el sistema financiero del Oriental hasta su fusión en 1909. Estas empresas estuvieron dirigidas por Manuel Rivero Collada y en ellos participaron accionistas, directivos y empleados. ${ }^{12}$

El contexto legal fue un factor positivo para el desarrollo de la empresa, pero tam-

11 Ludlow, "Primera", 1993, pp. 358-359. El artículo 11 de la Ley de Instituciones de Crédito establecía que las sociedades anónimas que explotaban el negocio financiero debían sujetarse, en todo lo que no estaba contemplado en la mencionada Ley, al Código de Comercio de 1884. Si bien el Código de Comercio de 1889 era el inmediato anterior, este Cóxligo sólo suprimía los preceptos que el Código de 1884 contenía en materia bancaria.

12 Leticia Gamboa muestra la similițud de los Consejos de Administración del Banco Oriental, Bunco de Oaxaca, Descuento Español y Refaccionario Español. Gamboa, "Banco", 2003, p. 132. Asimismo se conoce que los empleados del Oriental podían ser trasladados entre estas instituciones. Lorenzo, "Banqueros", 2001, p. 207. 
bién las oportunidades que ofrecía el mercado fueron, sin duda, alicientes para la expansión del Banco. El primer negocio del Oriental fue la difusión de su billete y, con base en la forma como se organizó la circulación de este papel, sabemos que el Banco promovió, sobre todo, el billete de baja denominación, ${ }^{13}$ aprovechando que, entre 1896 y 1910 , las ventas al menudeo registraron un periodo de auge en la región poblana. ${ }^{14}$

En otros negocios, a través del Descuento Español, los propietarios del Banco Oriental realizaron operaciones financieras en la ciudad de México, Puebla y en Verạcruz, las cuales estaban restringidas para los bancos de emisión por la ley de 1897. ${ }^{15}$ Es decir, sin comprometer la concesión otorgada al Banco Oriental, los dueños de éste expandieron las operaciones de cambio y de crédito en estas entidades. De tal manera, el Descuento funcionó como ban-

${ }^{13}$ AGN, Antiguos Bancos de Emisión, Banco Oriental de México, Libro de actas, 1.22.7, acta núm. 856,10 de junio de 1913 , p. $172 \mathrm{v}$., y Lorenzo, "Banqueros", 2001, p. 67.

${ }^{14}$ Cervantes, "Cambios", 1993, pp. 103-104.

15 El Descuento Español se constituyó en mayo de 1904 ante el notario Patricio Carrasco de Puebla. Se creó como Sociedad Anónima sin concesión oficial de la Secretaría de Hacienda y, en consecuencia, se rigió por el Código de Comercio de 1884. En el Descuento Español participaron accionistas y funcionarios del Oriental: el mismo grupo empresarial dirigió la administración, la contabilidad y los negocios de ambas instituciones, que en algunos casos se vislumbraban como una misma entidad. Grave crisis bancaria y pánico. El Descuento Español, 11 de enero de 1914, en Archivo Histórico de la Embajada de España en México (en adelante AHEEM), Archivo Antiguo, rollo núm. 47, leg. 4, núm. 4, política, y AGN, Antiguos Bancos de Emisión, Banco Oriental de México, Libro de actas, 1.22.3, acta núm. 193, 11 de febrero de 1904 , p. $10 \mathrm{v}$. co de compensación de los billetes del Oriental en la ciudad de México. ${ }^{16}$ También, por medio del Descuento, los consejeros del Oriental efectuaron operaciones de crédito con prenda de algoclón, sobre todo, en beneficio de la industrial poblana. ${ }^{17}$ Además de los negocios de emisión, cambio de billete y créditos prendarios, el Descuento funcionó como intermediario en la compraventa de vainilla, entre otros productos agropecuarios. ${ }^{18} \mathrm{Y}$ fue así como los promotores del Banco incursionaron en el dinámico mercado de este producto que representó entre 2 y $3 \%$ de las exportaciones del país durante el porfiriato. ${ }^{19}$

${ }^{16}$ Se entiende por compensación el proceso de cancelar pruebas de endeudamiento equivilentes, tales como cheques, pagarés, pagos comerciales, etc., con tal de obviar los pagos en dinero efectivo. Kindleberger, Historia, 1988, p. 638. De acuerdo con el sistema bancario que se estableció en México después de la publicación de la Ley de Instituciones de Créclito de 1897, se autorizó la concesión de bancos de emisión en cada estado, pero se prohibía el establecimiento de los mismos en la capital del país; así, resultaba indispensable una institución que funcionara como cámara de compensación. Esta función la realizó el Banco Central, aunque el Descuento compitió por esta función durante la crisis que registró el Banco Central en 1913. AGN, Antiguos Bancos de Emisión, Banco Oriental de México, Libro de actas, 1.22.7, acta núm. 860, 25 de julio de 1913, p. 178v. El Banco Central fue rescatado por las autoridades y por los bancos que recibían sus servicios; en consecuencia, la propuesta del Descuento para suplir al Central no se consolidó.

${ }^{17}$ AGN, Antiguos Bancos de Emisión, Banco Oriental de México, Libro de actas, 1.22.4, acta núm. 579,8 de mayo de 1909, p. 85.

${ }^{18} \mathrm{~A}$ través de la sucursal establecida en Teziutlán (Puebla), el Oriental concedió créditos para el negocio de la engorda de ganado y también participó con los productores de raíz de zacatón. Lorenzo, "lianqueros", 2001, pp. 68-75.

${ }^{19}$ Cosío, Historia, 1994, t. vir, pp. 106-107. 
De la primera sucursal a la fusión de los bancos de Oaxaca y Chiapas

La política de expansión del Banco Oriental definió su presencia en Veracruz y la ciudad de México, pero los consejeros del Oriental también se ocuparon del desarrollo del negocio financiero en los estados de Oaxaca y Chiapas. En este sentido, como lo ha señalado Leticia Gamboa, desde los primeros años de operaciones, los propietarios del Oriental concibieron la expansión de su empresa en la región sur oriental del país; por ello, éste adquirió el nombre de Banco Oriental de México y no el de Banco de Puebla. ${ }^{20}$

Los vínculos comerciales y la convergencia de capitales fueron factores que impulsaron el crecimiento de la empresa bancaria poblana hacia Oaxaca: los estrechos lazos comerciales y las relaciones de amistad y parentesco entre los miembros del Consejo de Administración y algunos empresarios del valle de Oaxaca facilitaron la instalación de la primera sucursal del Oriental en Oaxaca (1901). ${ }^{21}$

Para continuar con el desarrollo de los negocios del grupo financiero hacia el oriente del país, en 1905, los consejeros del Oriental compraron las acciones y los bonos fundadores del Banco de Chiapas, $y$

${ }^{20)}$ Gamboa, "Banco", 2003, p. 101.

${ }^{21}$ Leticia Gamboa señala que una de los principales vínculos entre los accionistas del Oriental y los del Banco de Oaxaca fue Vicente Gutiérrez Palacios (consejero del Oriental). Éste era primo de la suegra de Manuel Rivero Collada (presidente del Consejo del Oriental), y ambos amigos de Ángel Solana, inmigrante español que se estableció recién llegado en Huajuapan y que a finales del xix se trasladó a Puebla, dejando en Oaxaca parientes y amigos con los que continuó sus relaciones de afecto y negocios. Gamboa, "Banco", 1998, y "Banco", 2003. así promovieron sus billetes, prestaron sus servicios a los constructores del Ferrocarril Panamericano y participaron en el negocio de la especulación de moneda de plata que circulaba en la región fronteriza de Chiapas. $^{22}$

Finalmente, la expansión del Oriental se consolidó con la fusión de los bancos de Oaxaca y Chiapas en $1909 .^{23}$ Y como una ventaja en el proceso de fusión de los bancos, la Secretaría de Hacienda concedió al Oriental las posibilidades de establecer sucursales en Tlaxcala. ${ }^{24}$ Por consiguiente, a partir de 1909 , el Oriental obtuvo la concesión de primer banco de emisión en los estados de Puebla, Oaxaca, Chiapas y Tlaxcala.

Algunos años después, cuando la revolución mexicana se había iniciado, los promotores del Oriental fundaron una nueva empresa dedicada al negocio bancario. $\mathrm{Ri}$ vero Collada y sus socios crearon el Español Refaccionario S. A., y ésta fue la última institución promovida por el grupo de empresarios del Oriental. ${ }^{25}$ Referente

${ }^{22}$ Memoria, 1905, p. 129; AGN, Antiguos Bancos de Emisión, Banco Oriental de México, Libro de actas, 1.22.3, acta núm. 292, 11 de septiembre de 1905, p. $145 \mathrm{v}$; acta núm. 317,24 de enero de 1906, p. 195 , y Conant, Banking, 1910, pp. 222-225, 275.

${ }^{23}$ AGN, Antiguos Bancos de Emisión, Banco Oriental de México, Libro de actas, 1.22.4, acta núm. 560,30 de enero de 1909 , p. 47.

${ }^{24} \mathrm{Ibid}$, acta núm. 569, 6 de marzo de 1909, p. 60, y acta núm. 576, 17 de abril de 1909, pp. 7 lv-73.

${ }^{25}$ El Español Refaccionario S. A. se estableció en Puebla el 15 de diciembre de 1911 ante el notario Patricio Carrasco; careció, como el Descuento Lispañol, de la concesión oficial de banco y, por ello, aunque realizaba operaciones bancarias, no estuvo autorizado para emplear el apelativo de banco en su razón social; asimismo, estuvo regido por el Código de Comercio de 1884 . 
al objetivo del Refaccionario, hasta ahora no se cuenta con documentación que sustente que la institución funcionaba como una fuente de liquidez para los empresarios del Banco. Pero debido a la carestía del crédito, suscitado en el periodo revolucionario y a los "escasos negocios" que proporcionaban los créditos refaccionarios para los accionistas del Oriental, ${ }^{26}$ es posible que el Español Refaccionario fuera un instrumento para capitalizar a sus socios durante la revolución. ${ }^{27}$

Los propietarios del Oriental aprovecharon las coyunturas institucionales y trazaron el camino para una expansión exitosa del negocio financiero. En esta empresa, como en otras dirigidas por inmigrantes españoles, los directivos estrecharon vínculos comerciales con sus familiares y conterráneos, los cuales favorecieron el crecimiento y desarrollo del Banco. ${ }^{28} \mathrm{La}$ colaboración entre paisanos, parientes y amigos otorgaba confianza a la gestión de las empresas y, al mismo tiempo, concedía beneficios mutuos para sus participantes. En la práctica de la administración interna, esta reciprocidad se concibió como un

${ }^{26}$ En la primera asamblea de accionistas del Refaccionario, los consejeros especificaron que los créditos refaccionarios presentaban "algunas dificultades $\mathrm{e}$ inconvenientes", por ello, las negociaciones agrícolas o mineras difícilmente las aceptan. Atendiendo esta problemática, "las operaciones sólo alcanzaban la cifra aproximada de 200000.00 pesos". Primera, 1913. (Agradezco a Fernando Rivero Lira el haberme proporcionado este documento.)

${ }^{27}$ Ludlow, "Empresarios", 1994, p. 158.

${ }^{28} \mathrm{Al}$ respecto se puede consultar los casos de Antonio de Basagoiti y Manuel Rivero Collada estudiados rigurosamente por Carlos Marichal y Leticia Gamboa. Marichal, "Banca", 1999, y Gamboa, "Manuel", 1999. factor de fortalecimiento del Banco. Como veremos a continuación, acorde con los mecanismos sociales de los españoles en México, los directivos de la empresa emplearon preferentemente a los miembros de esta comunidad de extranjeros; capitalizaron la honorabilidad de los empleados avalada por otros inmigrantes, y aprovecharon la capacitación mercantil que los dependientes recibían, con anterioridad, en los negocios de sus conterráneos.

\section{LA POLÍTICA LABORAL COMO INSTRUMENTO DE LA EXPANSIÓN BANCARIA}

Los lazos familiares, el paisanaje y la organización social de la comunidad de españoles en México fueron aspectos decisivos para el desarrollo del Banco Oriental de México. Entre 1900 y 1915, el Consejo del Banco estructuró un sistema laboral que favoreció a los parientes y conterráneos de los directivos de la empresa. No obstante, los consejeros del Oriental aplicaron diversas normas de disciplina y ética comercial para sistematizar los vínculos familiares, de amistad y paisanaje en beneficio del negocio.

La organización interna de la institución recayó principalmente en Manuel Rivero Collada. A pesar de la centralización de funciones, ejercida por Rivero Collada, de manera formal, este empresario debía compartir con el gerente del Banco, Manuel Rangel, algunas actividades directivas. Pero, según se observa en la práctica de los negocios y la organización del Banco, Rangel, quien ocupó el cargo de gerente de la institución hasta la incautación del Oriental en 1915, careció de un papel activo en la empresa, y más bien actuaba como secretario particular de Rivero Co- 
llada en lo relativo a la organización del Banco. $^{29}$

La creación de comisiones, conformadas por dos o tres consejeros, contribuyó también a ejecutar y verificar disposiciones específicas del Consejo. Sin embargo, las comisiones sólo ejercieron una actividad coyuntural en la organización del Banco. ${ }^{30}$ Por consiguiente, advertimos que si bien había una organización formal para la delegación de funciones administrativas, en la práctica, Manuel Rivero Collada -con cierto apoyo del gerente y algunos consejeros-fue quien realmente organizó los negocios y el desarrollo interno de la empresa.

Las relaciones sociales y comerciales que adquirió Rivero Collada a través de su matrimonio con la hija de Alejandro Quijano (un prominente hombre de negocios de origen español) fueron un factor significativo para su ascenso en el mundo de los negocios en México. En combina-

${ }^{29} \mathrm{El}$ reglamento interior del Banco Oriental de México estipuló las funciones del "director o gerente". Si bien en la práctica parece que la labor gerencial la ejecutó Manuel Rivero Collada, esto no supuso la desaparición del cargo de gerente de las oficinas, el cual detentó Manuel Rangel. Al respecto, es de notar que, según lo estipulaba el reglamento, el gerente Rangel funcionó como secretario en las juntas semanales celebradas por el Consejo de Administración. (Agradezco a la doctora Leticia Gamboa el haberme proporcionado una copia del Reglamento interior del Banco Oriental de México.)

${ }^{30}$ En noviembre de 1903 , el Consejo estipuló que la Comisión de Negocios cedería sus funciones a Manuel Rivero Collada para que éste negociara los términos del primer aumento de capital con el Banco Hispano Americano. AGN, Antiguos Bancos de Emisión, Banco Oriental de México, Libro de actas, 1.22.2, acta núm. 175,17 de noviembre de 1903 , p. 124. ción con su habilidad y dedicación, estos vínculos sociales hicieron factible la dirección de las empresas familiares, de los que el Banco Oriental formaba parte, lo cual le permitió "tener en sus manos un haz de valiosos hilos que lo mantenían al tanto de la marcha de los negocios en Puebla y en el país". ${ }^{31}$ De tal manera, su primacía en los negocios no fue casual. La reputación social y el desempeño empresarial de Rivero Collada le concedieron el ingreso a una elite de dinámicos hombres de negocios que lograron diferenciarse del "mercader" o del abarrotero local, personificando a un empresario de nuevo cuño que, como ha señalado Carlos Marichal, para otros empresarios españoles reflejaba un proceso de modernidad y mayor complejidad en la economía mexicana de la época. ${ }^{32}$

\section{El reclutamiento y la selección de personal}

El reclutamiento de personal del Banco fue definitivo para asegurar una planta laboral estable, de confianza y con cierta capacitación. El profesionalismo, la honestidad, la lealtad a la empresa, la disciplina en el trabajo, el cuidado del aspecto personal y una vida social acorde con las buenas costumbres de la época conformaron un grupo de empleados homogéneo y confiable. Según se comprueba a través de los empleados elegidos por el Consejo, las cualidades personales y la reputación necesaria para laborar en el Banco se demostra-

${ }^{31}$ Gamboa, "Manuel", 1999, p. 808. Esta práctica fue una característica de la empresa familiar durante el siglo XIX; Valdaliso y López, Historia, 2000, p. 208.

${ }^{32}$ Marichal, "Banca", 1999, p. 769. 
ban, previamente, con el trabajo que estos empleados habían realizado en otros negocios. En este aspecto, los miembros de la comunidad de españoles establecidos en México se convirtieron en el aval y la referencia para aquellos que se incorporaron como empleados del Banco.

En general, los dependientes del Banco eran hombres adultos, entre los 28 y los 50 años de edad, miembros de las familias de los consejeros, accionistas o de los empleados de alto nivel. Además, estos dependientes contaban con la recomendación familiar o con la referencia de una casa comercial o, en su defecto, con el antecedente laboral remitido por ciertas dependencias gubernamentales. Así, los empleados reclutados tenían cierta experiencia en materia mercantil y un aval que los refería como personas "honradas y de buenas costumbres". ${ }^{33}$

Con base en el perfil de la población hispánica en México, realizado por Clara Lida, entre 1905 y 1929, los españoles ingresaban en el país entre los quince y los 25 años de edad. Esta población joven y soltera se concentraba en áreas productivas que requerían poca experiencia y capacitación. ${ }^{34}$ Por consiguiente, es posible advertir que el Banco no contrató a los españoles recién llegados, pero sí empleó a aquellos que tenían cierta formación ges-

${ }^{33}$ Las cartas de recomendación indicaban, por ejemplo, que el empleado "es joven, trabajador, honrado de buenas costumbres", "que conoce bastante de contabilidad, pues la mayor parte de su tiempo lo ha dedicado a empleos en varias oficinas" o que era "hombre de aptitudes y buena conducta", en AGN, Antiguos Bancos de Emisión, Banco Oriental de México, Libro de actas, 1.22.7, acta núm. 824,25 de noviembre de 1912 , p. 11.0 , y acta núm. 836,27 de enero de 1913, p. $131 \mathrm{v}$.

${ }^{34}$ Lida, Inmigración, 1994, pp. 43-45. tada a partir de la experiencia laboral realizada en México en otros negocios.

El sistema de reclutamiento aplicado por los consejeros del Banco Oriental de México tuvo cierta similitud con un mecanismo presente entre los inmigrantes españoles para emplear a sus parientes y conteráneos en sus negocios. Este mecanismo, que se ha denominado inmigración en cadena, consistía en que el comerciante español establecido en México, que contaba ya con una posición económica estable, traía de España a algún pariente joven o conocido cercano para que colaborara en los trabajos más pesados en el negrocio. El recién llegado desarrollaba relaciones con una amplia gama de comerciantes y establecía paulatinamente su reputación. Esta especie de aprendiz trabajaba como empleado de confianza (cajero o vendedor) hasta que el patrón consideraba que podía independizarse $o$, en algunos casos, convertirse en socio o dueño. Para lograr la independencia, una vez concluido su entrenamiento, el antiguo residente le entregaba al empleado la parte de su salario guardado durante el tiempo que había trabajado en el negocio, aunque también podía instalar su propio negocio con el apoyo financiero de algún pariente o de un socio comercial. Dicho sistema brindaba a los inmigrantes españoles una red de relaciones establecidas previamente en México, la cual facilitaba el desarrollo de sus actividades. Los promotores del Banco, que en su mayoría eran de origen español, conocían bien el mecanismo de la inmigración en cadena como medio de ascenso socioeconómico y así lo aplicaron en beneficio de su empresa. ${ }^{35}$

${ }^{35}$ Respecto del mecanismo de inmigración en cadena a finales del siglo XIX y principios del $\mathrm{xx}$ se 
En efecto, en el caso específico del Oriental, los lazos nacionales y de parentesco favorecieron el ingreso del personal de confianza en el Banco. Asimismo, los beneficios proporcionados por la empresa financiera contribuyeron al bienestar de sus empleados. Sin embargo, el Oriental, a diferencia de lo que sucedía en otros negocios de inmigrantes españoles, no ofreció a sus dependientes la posibilidad de independizarse o convertirse en accionistas o dueños; pero, en cambio, las prestaciones otorgadas por el Banco a sus empleados eran atractivas para la época y concedían cierto bienestar laboral y económico para sus empleados.

La experiencia adquirida por los españoles a través de la propia comunidad, en los negocios de otros conterráneos, eventualmente podía ser capitalizada por el Banco al contratarlos como sus empleados. ${ }^{36}$ Así, los que al llegar a México lograron cierta instrucción en materia mercantil con el tiempo se convirtieron en el

pueden consultar los siguientes trabajos: García, "Integración", 1979, p. 95; Pérez, "Algunas", 1979, p. 135; Lida, "Españoles", 1988, p. 331; "Inmigración", 1991, p. 201-215, Inmigración, 1994, p. 147, y Marichal, "Banca", 1999, p. 773.

${ }^{36}$ Por ejemplo, Manuel Rivero Collada, presidente del Consejo del Banco Oriental, recomendó al español Manuel Asomoza, quien había trabajado como tenedor de libros en su casa. Entonces, el Consejo determinó que se emplearía al señor Manuel Asomoza en la primera oportunidad, "con un sueldo aproximado de 200 pesos mensuales". Un año más tarde, el recomendado ocupó el cargo de gerente en la sucursal de Atlixco. AGN, Antiguos Bancos de Emisión, Banco Oriental de México, Libro de actas, 1.22.5, acta núm. 595,5 de julio de 1909 , p. 115 v; acta núm. 592, 2 de agosto de 1910; Libro de actas, 1.22.6; acta núm. 707, 18 de mayo de 1911, p. 36v-37, y AHEEM, caja 229, viceconsulado de Puebla, 21 de septiembre de 1896, leg. 11, núm. 1, f. 8. capital humano aprovechado por el Banco para conformar su planta laboral. Consiclerando que durante los primeros años del siglo xx en México no existían estudios profesionales en materia financiera, la experiencia práctica obtenida por los inmigrantes españoles en sus primeros pasos en México dentro de la colectividad de españoles se tradujo en una ventaja comparativa respecto de otros aspirantes que carecían de esta formación. Lo anterior explica también, en cierta forma, la preferencia de los directivos de la empresa para contratar a los miembros de la propia comunidad que ya tenían experiencia y gozaban ya de confranza.

Cabe señalar que, desde los primeros años de operación, el Consejo ejerció un control estricto en el reclutamiento de personal. Este control se mantuvo durante el proceso de instalación de las 17 sucursales del Oriental y la apertura de las oficinas del Descuento Español y del Refaccionario que, a partir de 1909, en conjunto emplearon entre 60 y 70 personas. ${ }^{37}$ El Banco Oriental pudo ejercer una selección cuidadosa y, a cambio, ofrecer ventajas comparativas respecto de otros negocios. Por ejemplo, en algunas solicitudes y recomendaciones para dependientes del Orien-

37. Una situación representativa de este control fue lo suscitado en la sucursal de Tlaxcala durante 1912, cuando el conserje Manuel Ramírez renunció a su cargo. Para suplir esta labor, el gerente nombró a Federico Madrid, quien "tenía varias recomendaciones y es generalmente conocido como de toda confianza". El Consejo aprobó el nombramiento, pero advirtió que "según las disposiciones vigentes, ni provisionalmente, [el gerentel debe hacer nombramitntos de empleados o sirvientes, sin consultar previamente a esta matriz". AGN, Antiguos Bancos de Emisión, Banco Oriental de México, Libro de actas, 1.22.7, acta núm. 817, 17 de septiembre de 1912, p. 87. 
tal se destaca que los aspirantes no carecían de empleo, pero que buscaban una mejor opción laboral, como la que el Banco ofrecía. $^{38}$

En suma, el sistema de reclutamiento del Oriental privilegió el ingreso de un grupo específico de la población española en México, pero también aseguró al Banco una planta laboral homogénea, capacitada y confiable, factores que, como apuntaremos en los siguientes apartados, fueron esenciales para el buen funcionamiento de la empresa.

\section{La distribución de los salarios}

Las relaciones personales y de negocios, el parentesco y las recomendaciones definieron la distribución de los salarios entre los empleados del Banco. La confianza -gestada a partir del desempeño eficiente de las labores, de los lazos de parentesco y de las referencias laborales-incidía en las retribuciones de los empleados.

Los dependientes de origen español utilizaron los lazos de origen común para atraer diversos negocios a la empresa; en compensación, el Banco los retribuyó con salarios ventajosos. Así, estos empleados, que contaban en el país con una red social y comercial estructurada, obtuvieron beneficios salariales, a la vez que aportaban a la empresa sus vínculos personales y comerciales previos. Ejemplo de ello es el caso

${ }^{38}$ Entre 1900 y 1915 , la organización de la casa matriz y de las sucursales experimentó transformaciones significativas. No obstante, Rivero Collada encabezó, invariablemente, el organigrama. Lorenzo, "Banqueros", 2001, pp. 151, 170, 172. Véase el cuadro 1 con el objetivo de mostrar las diversas funciones administrativas que realizaban los empleados del Banco Oriental en 1909. del gerente de Tapachula, Manuel Ugas Crespo, quien obtuvo un incremento salarial cuando logró un negocio financiero para el Banco con José Revuelto, un prominente español de esa localidad. Este comerciante era propietario de negocios de café, pieles y hules; además, era dueño de las haciendas Alianza y Delicias, entre otras empresas mercantiles en Chiapas. Asimismo, era cónsul de España en la entidad ${ }^{39}$ Revuelto llevaba sus negocios con el Banco Nacional; sin embargo, el gerente Ugas Crespo aseguró al Consejo que Revuelto le había prometido "algunos negocios garantizados con su firma" debido a su "relación amistosa". 40 Es así como las relaciones sociales del gerente de Tapachula beneficiaron los negocios del Banco $y$, para él, se convirtieron al mismo tiempo en una ventaja salarial. ${ }^{41}$

La política de asignación de sueldos del Oriental obedecía a una lógica ajena a la estructura de puestos, pero esto no implicó que las retribuciones fueran otorgadas de manera arbitraria y, puesto que la confianza fortalecía la buena marcha de los negocios, según perfilaron los promotores del Oriental, los sueldos del Banco se concedieron también con base en los lazos familiares. Un claro ejemplo es el de José Rivero Collada, hermano de Manuel Rivero Collada, presidente del Consejo de Administración, quien recibió la retribución

${ }^{39}$ Dollero, México, 1911, p. 875.

${ }^{40}$ En AGN, Antiguos Bancos de Emisión, Banco Oriental de México, Libro de actas, 1.22.4, acta núm. 605, 11 de septiembre de 1909, p. 151 .

${ }^{41}$ El salario asignado a Ugas Crespo fue de 3600 pesos anuales. Esta retribución era equivalente a la del contador del banco Miguel Buega. Ugas Crespo recibió un salario comparativamente alto, considerando que, en la estructura de puestos, el gerente de sucursal dependía del contador. 


\section{Cuadro 1}

La organización de la casa matriz en 1909



más alta registrada entre los empleados del Banco Oriental, Banco de Oaxaca, Descuento Español y Refaccionario Español, cuando ocupó el cargo de gerente del Descuento. ${ }^{42}$ Asimismo, los empleados de confianza, es decir, aquellos dependientes con una recomendación especial, también obtuvieron ciertos privilegios en el esquema de la distribución salatial y recibieron un sueldo conforme a las expectativas de quien los recomendaba. Un ejemplo de esto fue el caso del empleado José Solís que solicitó un aumento salarial argumentando "lo complicado y laborioso

\footnotetext{
${ }^{42} \mathrm{El}$ salario asignado fue de 6000 pesos anuales. AGN, Antiguos Bancos de Emisión, Banco Oriental de México, Libro de actas, 1.22.4, acta núm. 554, 14 de enero de 1909, p. 41.
}

de los trabajos". El Consejo decidió que su labor no justificaba dicho incremento; sin embargo, el presidente Manuel Rivero Collada intercedió, señalando que Solís era recomendado de Adolfo Prieto (director de la Fundidora de Hierro y Acero de Monterrey), y que éste tenía la impresión de que la plaza propuesta para Solís se remuneraría con 150 pesos mensuales. Por ese motivo, el Cốnisejo reconsideró la negativa y concedió el salario que Prieto esperaba para Solís. ${ }^{43}$

El reparto discrecional de los salarios fue posible debido a la centralización de esta función. Es cierto que en los libros de actas se asentaba que "el Consejo" de-

4.3 Ibid., Libro de actas, 1.22.3, acta núm. 258, 6 de marzo de 1905 , p. 91. 
terminaba los salarios y excepcionalmente aceptaba la sugerencia de los gerentes y consultores de las sucursales. ${ }^{44}$ No obstante, en la práctica, Manuel Rivero Collada era quien asignaba los salarios de todos los empleados, ejerciendo las facultades que le concedía su doble función de presidente y delegado del Consejo.

Durante los primeros años de operación, los salarios se revisaron, cuando menos, una vez al año. En este periodo, no se registraron inconformidades relativas a las retribuciones ni tampoco hubo solicitudes de aumento. ${ }^{45}$ En cambio, a partir del inicio de la revolución mexicana, proliferaron las peticiones de incremento salarial y de créditos personales, lo cual apunta a cierto encarecimiento de la vida y a mayores dificultades económicas en este periodo. ${ }^{46}$

${ }^{44}$ El consultor y el gerente de la sucursal de Teziutlán sugirieron al Consejo de Administración la cantidad que debían pagar a los empleados Luis Santiago (70 pesos mensuales) y Manuel Bello (50 pesos mensuales). Por el monto sugerido, advierto que éstos ocuparían los puestos de meritorios y auxiliar de caja, empleos que estaban subordinados al gerente y cajero contador de la sucursal. AGN, Antiguos Bancos de Emisión, Banco Oriental de México, Libro de actas, 1.22.4, acta núm. 577, 23 de abril de 1909, p. 76 .

${ }^{45} \mathrm{La}$ primera solicitud de aumento de salario registrada en el banco la interpuso José Solís; no obstante, esta solicitud fue excepcional y sólo después de 1912 estos requerimientos proliferaron. AGN, Antiguos Bancos de Emisión, Banco Oriental de México Libro de actas, 1.22.3, acta núm. 258, 6 de marzo de 1905 , p. 91.

${ }^{46}$ Véanse los casos de Antonio González, Juan Ezeta y Francisco Ramírez, en ibid., Libro de actas, 1.22.7, acta núm. 807, 27 de julio de 1912, pp. 76, $77 \mathrm{v}$; Clemente Xicoy, acta núm. 824, 25 de noviembre de 1912, p. 110, y Nicanor Terán Ortiz y Merino Rivera, acta núm. 836, 27 de enero de 1913, p. 131v.
La movilidad de puestos, la obedicncia $y$ la disciplina laboral

En el Banco Oriental, los puestos eran mudables y los empleados podían ser desplazados de sus cargos según las necesidades de la empresa. Las vacantes, la apertura de nuevos puestos, los conflictos entre los empleados o el riesgo de la salud de algún funcionario fueron las causas más comunes para determinar el traslado de los dependientes de esta empresa financiera a otras responsabilidades. El objetivo de los desplazamientos era emplear al personal capacitado y de confianza en las vacantes y nuevos cargos que surgían en el Banco. Es decir, debido a que los empleados del Oriental recibían parte de su instrucción en el ejercicio de sus labores, la movilidad de los puestos se realizó con empleados capacitados. ${ }^{47}$

Por un lado, la confianza y el ejercicio de la práctica laboral posibilitaron la efectividad de una movilidad de puestos, la cual implicó, por otro lado, una estricta disciplina laboral para someterse a las disposiciones del Consejo. ${ }^{48}$ Esta disciplina

${ }^{47}$ Específicamente, en 1909, el Consejo estipuló que los nuevos dependientes contratados debían pasar un tiempo en la casa matriz "con el objeto de que se instruyan en las labores de nuestras oficinas y pasen después a prestar sus servicios en las sucursales que se vayan estableciendo". AGN, Antiguos Bancos de Emisión, Banco Oriéntal de México, Libro de actas, 1.22.4, acta núm. 605,11 de septiembre de 1909 , p. $1.52 \mathrm{v}$.

${ }^{48}$ Respecto de la normatividad de los empleados, hasta ahora sólo hemos localizado un reglamento interno que define, de manera general, el funcionamiento de las oficinas, aunque sabemos que los directivos normaban, a través de circulares que envialain a las sucursales, el comportamiento y los requisitos de disciplina necesarios para laborar en el Banco. Desconoce- 
no aceptó la inconformidad de los dependientes y se aplicó a cuantas quejas se presentaron. Sin embargo, de manera individual, algunos empleados manifestaron su desacuerdo. Por ejemplo, el cajero Alberto Huajuca mostró cierto inconveniente para desplazarse de Puebla a Tehuacán. A pesar de un incremento salarial de 400 pesos anuales, Huajuca argumentaba que no podía residir ni en Oaxaca ni tampoco en Tehuacán, porque en la primera había paludismo y en la segunda, además de resequedad atmosférica, el agua era de mala calidad. ${ }^{49}$ El Consejo ordenó que, a pesar de las condiciones desagradables, el empleado debía prestar los servicios encomendados en Tehuacán, "porque así lo exigen las necesidades del Banco, y la disciplina que debe haber en los empleados de la institución". ${ }^{50} \mathrm{Al}$ poco tiempo, Huajuca renunció.

En este sentido, la movilidad de puestos exigió una disciplina laboral estricta y el compromiso de la vida privada del empleado con el Banco. A cambio, las concesiones otorgadas por el Consejo a los empleados en otros renglones de la política laboral -como mejoras salariales y prestaciones- buscaban compensar el compromiso, la disciplina y el sometimiento a las disposiciones del Consejo.

mos si existe, como en otras instituciones, estatutos para empleados. (Agradezco a Leticia Gamboa el haberme facilitado una copia del Reglamento Interno del Banco Oriental.)

49 AGN, Antiguos Bancos de Emisión, Banco Oriental de México, Libro de actas, 1.22.4, acta núm. 594, 26 de junio de 1909, p. 112; acta núm. 595, 5 de julio de 1909 , p. 114v, y Libro de actas, 1.22.3, acta núm. 187, 19 de enero de 1904 .

${ }^{50} \mathrm{Ibid}$., Libro de actas, 1.22.4, acta núm. 595, 5 de julio de 1909 , p. $114 \mathrm{v}$.

\section{Gratificaciones, servicios y prestaciones}

Los empleados del Oriental recibieron algunas prestaciones especiales. Entre ellas, destacan los préstamos personales, la asistencia económica (en los casos de enfermedad del empleado o de sus familiares) y la vivienda otorgada a los gerentes y contadores que trabajaban en sus sucursales. Estas prestaciones, entre otras, significaban ventajas cuantiosas en los primeros años del siglo XX.

Los créditos personales fueron una prestación especial otorgada a los empleados, sobre todo, cuando el dependiente enfermaba o le sucedía alguna desgracia familiar. ${ }^{51}$ Cabe destacar que en estos casos hubo un trato deferente por parte del Consejo: a algunos les concedían el permiso de faltar con goce de sueldo, y a otros, que quizá carecían de familiares que los atendieran en México, además de una aportación en efectivo, el Banco les pagaba el viaje para su recuperación en la península. ${ }^{52}$ Además de la solidaridad manifiesta entre conterráneos, al considerar la capacitación y el conocimiento que adquirían los em-

${ }^{51}$ Ibid., Libro de actas, 1.22.7, acta núm. 81.8, 28 de octubre de 1912, p. 96v, y acta núm. 764,18 de diciembre de 1911 , p. $3 \mathrm{v}$.

${ }^{52}$ Jacinto Martínez se le auxilió en el caso de una aguda enfermedad. Se le otorgaron 200 pesos en efectivo y el pago del pasaje Puebla, Veracruz y "en tercera de primera" a un puerto en España". A José Piñera, empleado de la casa matriz, le pagaron un viaje "en primera clase a España" y le otorgaron " 100 pesetas para el viaje" cuando los médicos Quintana y O'Furril y A. Moreno le diagnosticaron tuberculosis. AGN, Antiguos Bancos de Emisión, Banco Oriental de México, Libro de actas, 1.22.4, acta núm. 537, 26 de septiembre de 1908 , p. 70, y Libro de actas, 1.22 .7 , acta núm. 852, 19 de mayo de 1913, p. 166. 
pleados del Banco en la práctica de sus labores, percibimos el interés de los promotores del Oriental por preservar la salud de sus empleados, en el sentido de que éstos no eran fácilmente reemplazables.

Otra prestación otorgada por el Banco Oriental a los empleados de confianza consistió en las habitaciones que el Banco destinaba, usualmente en sus oficinas. Sin embargo, es de notar que esta prestación también permitía al Consejo efectuar los traslados de la planta laboral del Banco, al facilitarles vivienda pronta. Es decir, a la vez las oficinas de las sucursales del Oriental, donde frecuentemente se custodiaban los valores depositados por los clientes, estaban resguardadas día y noche por los propios empleados de confianza.y sus familiares que vivían en el mismo edificio.

Para resumir, las gratificaciones, servicios y prestaciones concedidas por el Oriental se otorgaban a los empleados de confianza y a aquellos empleados que tenían vínculos de nacionalidad compartidos con los directivos del Banco, pero, al mismo tiempo, estas prestaciones fueron provechosas también para el desarrollo y la seguridad de la institución.

\section{Terminación de las relaciones de trabajo}

En el Banco Oriental, la terminación de las relaciones de trabajo fue poco común. De hecho, las pocas renuncias registradas en el Banco surgieron como consecuencia de cierta inconformidad frente al traslado de plaza, o debido a mejores ofertas de trabajo o por enfermedad. De éstas, el motivo más recurrente fue por enfermedad. Por otro lado, la suspensión temporal de los empleados se suscitó solamente cuando el Banco requirió aclarar algún procedimien- to penal que involucraba a los empleados de su empresa o para evitar que se rompiera un ambiente cordial en las oficinas..$^{53}$

Por su parte, las causas que provocaron la suspensión definitiva de los empleados fueron el incumplimiento en el trabajo, las faltas a la moral y el robo, ${ }^{54}$ aunque esto último se presentó de manera excepcional. ${ }^{55}$ La imagen pública de los empleados era un factor considerable para laborar en la empresa; en este sentido, los consejeros procuraron una vigilancia estricta en el comportamiento de los empleaclos dentro y fuera del Banco. Así, por ejemplo, el 15 de enero de 1912, el Consejo dispuso que se liquidara al gerente de Acatlán, porque éste tenía la costumbre de embriagarse y

${ }^{53} \mathrm{Ibid}$., Libro de actas, 1.22.7, acta núm. 770, 15 de enero de 1912, p. 16, y acta núm. 832, 20 de enero de 1913, p. 124.

${ }^{54} \mathrm{lbid}$., Libro de actas, 1.22.7, acta núm. 817, 17 de septiembre de 1912, p. 86v.

${ }^{55}$ Sólo encontramos un caso, cuando Enricjue del Valle, visitador del Banco Oriental, registró un faltante de 348 pesos en la caja de la sucursal de Santa Ana Chiautempan. Si consideramos que el sueldo anual de un gerente era de 3000 pesos, la canticlad faltante equivalía al pago mensual de un gerente, suma importante para una sucursal. Del Valle investigó al cajero contador de Santa Ana, Miguel Domínguez Toledano, quien manifestó que había tomado el dinero para sus "gastos particulares de carácter urgente". Si bien el Consejo de Administración comprendía que "el sueldo que gana como cajero contador escasamente le alcanza para subsanar las necesidades de su numerosa familia", atendiendo al principio de "moralidad que debe ser invulnerable en toda negociación más aún en una institución de crédito", el Consejo separó de su cargo al empleado que cometió la falta y lo obligó a pagar la suma del desfalco. AGN, Antiguos Bancos de Emisión, Banco Oriental de México, Libro de actas, 1.22.6, acta núm. 731, 28 de agosto de 1911, p. 108v, y acta núm. 733,4 de septiembre de 1911, p. $103 \mathrm{v}$. 
esto era sabido públicamente. ${ }^{56}$ Considerando la importancia que para el Banco tenían las relaciones sociales y la imagen pública de los empleados, la suspensión del dependiente de Acatlán se suscitó, principalmente, porque "la sociedad reconocía su costumbre de embriagarse". Es decir, no se trataba de que los empleados del Oriental fueran abstemios, sino que se les exigía un comportamiento aprobado por la comunidad para preservar su cargo en la empresa.

En este trabajo he destacado la presencia de los inmigrantes españoles entre los empleados del Banco. Al respecto, es de notar la permanencia de este grupo en la empresa bancaria hasta el inicio de la revolución mexicana; en esos años, únicamente José Manuel Camino, gerente de la sucursal de Oaxaca, notificó al Consejo su regreso a la península "por ser necesaria su presencia en España para atender asuntos de familia". ${ }^{57}$ Considerando lo expuesto, advertimos que los empleados españoles que trabajaban en esta institución no regresaron permanentemente a su país durante el periodo de 1900 a 1913 . Así, en efecto, participaron en el desarrollo de esta empresa financiera, a pesar del agitado contexto que se suscitó por la lucha armada a partir de 1910.

El advenimiento de la revolución mexicana marcó el final de los grandes negocios financieros de los promotores del Banco Oriental. Los préstamos forzosos y el recrudecimiento de la guerra propiciaron el descontrol en la emisión del circulante

${ }^{56}$ Ibid, Libro de actas, 1.22.7, acta núm. 770, 15 de enero de 1912, p. 16.

${ }^{57}$ Ibid., Libro de actas, 1.22.6, acta núm. 697, 23 de marzo de 1911, p. $7 \mathrm{v}$. de los bancos. ${ }^{58}$ En 1915, Venustiano Carranza ejecutó la incautación de los bancos, entre ellos el Banco Oriental de México, pues según argumentaron los inspectores, éste presentaba una situación "notoriamente desequilibrada" respecto de la garantía que la ley exigía en la circulación y emisión de billetes. ${ }^{59}$ Las transformaciones institucionales suscitadas durante la revolución cambiaron el rumbo de la banca comercial del porfiriato, y los aspectos institucionales que hemos examinado llegaron a su fin. Asimismo, con la Constitución de 1917, a través del artículo 123 , se trazaron los lineamientos generales que, paulatinamente, modificaron las relaciones entre los patrones y los empleados. Esto no sólo afectó a los nacidos en México, sino también a los extranjeros que participaban en los negocios y en las empresas del país.

\section{CONSIDERACIONES finAles}

Si bien se ha mostrado que, durante 1900 y 1915, los promotores del Oriental participaron en el negocio de emisión de billetes, en la industria textil poblana y en importantes transacciones agropecuarias en la región, el núcleo del trabajo examinó cómo las redes sociales y comerciales características del grupo de inmigrantes españoles en México sustentaron el desarrollo del Banco. Los promotores del Oriental aprovecharon sus vínculos familiares, nacionales y de amistad en beneficio del negocio, lo cual les permitió estructurar una

${ }^{58}$ Respecto del desarrollo del sistema bancario en México durante el periodo tevolucionario se puede consultar el trabajo de Anaya, Colapso, 2002.

${ }^{59}$ Manero, Revolución, 1991, p. 110. 
planta laboral estable, capacitada y de confianza. A través de algunos aspectos de la política laboral, Manuel Rivero Collada, representante de una cúpula empresarial dinámica y modernizadora, capitalizó las relaciones comerciales, los vínculos de parentesco y las redes sociales que fomentaron la eficiencia y la modernización de la banca comercial gestada durante el porfiriato.

Por su parte, los empleados aprovecharon los beneficios que les ofrecía el sistema bancario del Oriental y aceptaron las condiciones impuestas por la empresa para trabajar en ella. Algunos aportaron, incluso, sus propias relaciones sociales y comerciales previas, y con ello fomentaron el proceso de la expansión bancaria; pero, a la inversa, la empresa también fue para estos inmigrantes un medio de prosperar en México. Así, las buenas aldabas que lograron los españoles, al vincularse con sus conterráneos en México, tuvieron ventajas recíprocas. Para el Banco constituyeron un factor de desarrollo y, para aquellos que llegaron al país a finales del siglo XIX, esto fue un medio de trabajo no sólo digno, sino ventajoso. Los españoles establecidos en México se incorporaron a una de las instituciones financieras más destacadas del porfiriato, participando de su crecimiento. De este modo, el Oriental y sus empleados estuvieron íntimamente ligados en su desarrollo hasta la revolución.

\section{FUENTES CONSULTADAS}

\section{Archivos}

AGN Archivo General de la Nación.

AHEEM Archivo Histórico de la Embajada de España en México.

\section{Bibliografía.}

-Anaya Merchant, Luis, Colapso y reforma. La integración del sistema bancario en el México revolucionario 1913-1932, Miguel Ángel Porrúal Universidad Autónoma de Zacatecas, México, 2002.

-Ángel, Gustavo A. del y Carlos Marichal, "Poder y crisis: historiografía reciente del crédito y la banca en México, siglos XIX y XX", Historia Mexicana, vol. LII, núm. 207, 2003, pp. 677-724.

-Barrera Lavalle, Francisco, Estudios sobre el origen, desenvolvimiento y legislación de las instituciones de crédito en México, Tipografía de García y Compañía, México, 1909.

-Cameron, Rondo, Historia económica mundial. Desde el paleolítico basta el presente, Alianza, Madrid, 1998 (Alianza Universidad Textos, 134).

-Cassis, Youssef, City Bankers, 1890-1914, Cambridge University Press, Cambridge, 1994.

-Cerutti, Mario y Carlos Marichal (comps.), La banca regional en México (1870-1930), COLMEX/FCE, México, 2003.

-Cervantes Bello, Francisco Javier, "Los cambios en el mundo del dinero: comercio, crédito y finanzas" en Carlos Contreras Cruz (comp.), Puebla una bistoria compartida, Instituro Moral ICSH-Universidad Autónoma de Puebla, México, 1993, pp. 90-106.

-Chandler, Alfred D. Jr., La mano visible. La revolución en la dirección de la empresa norteamericana, Ministerio de Trabajo y Seguridad Social, Madrid, 1987.

-Conant, Charles, The Banking System of $\mathrm{Me}$ xico, The National Monetary Commission, Washington, 1910.

-Cosío Villegas, Daniel, Historia moderna de México. El porfiriato, la vida económica, Editorial Hermes, Colombia, 1994, t. viI.

-Dollero, Adolfo, México al día, Librería de la Viuda de Bouret, México, 1911. 
-Gamboa Ojeda, Leticia, Los empresarios de ayer. El grupo dominante en la industria textil de Puebla. 1906-1929, Universidad Autónoma de Puebla, Puebla, 1985.

"El Banco Oriental de México y la formación de un sistema de banca, 1900-1911", ponencia presentada en El Colegio de México el 28 y 29 de enero de 1998 en coloquio: Orígenes de la Banca Regional en México: Una Perspectiva Comparada, 1870-1930, México, 1998.

, "Manuel Rivero Collada. Negocios y política en Puebla, 1897-1916", Historia Mexicana, vol. xIVIII, núm. 4 (192), 1999, pp. 795-823. , "El Banco Oriental de México y la formación de un sistema de banca, 1900-1911" en Mario Cerutti y Carlos Marichal (comps.), La banca regional en México (1870-1930), COLMEX/FCE, México, 2003, pp. 101-133.

-García Acosta, Virginia, "La integración económica de los españoles en la ciudad de Puebla y los asturianos en el Distrito Federal" en Michael Kenny et al., Inmigrantes y refugiados españoles en México, siglo XX, La Casa Chata, México, 1979, pp. 95-129 (Centro de investigaciones del INAH, 8).

-García López, José Ramón, Las remesas de los emigrantes españoles en América, siglos XIX y XX, Ediciones Júcar/Archivo de Indianos, Colombres, Asturias, 1992.

-García Ruiz, José Luis, "Internal Organization and Growth in the National Banks: The Case of the Banco Hispano Americano and the Banco Central, 1901-1991", Social Science Research Network Electronic Library, JEL (Journal of Economic Literature), L22, N84, Working Papers Series, 2000.

-Gómez, Mónica, "El crecimiento de la banca local de emisión en México, 1897-1910" en Mario Cerutti y Carlos Marichal (comps.), $L a$ banca regional en México (1870-1930), COLMEX/ FCE, México, 2003, pp. 321-345.

-Hilferding, Rudolf, El capital financiero, Instituto Cubano del Libro, La Habana, 1971.
-Hill, John, From Subservice to Strike, University of Queensland Press, St. Lucía, Queensland, 1982.

-Kindleberger, Charles P., Historia financiera de Europa, Crítica, Barcelona, 1988.

-Lida, Clara E., "Los españoles en México. Del porfiriato a la post-revolución" en Nicolás Sánchez Albornoz (comp.), Españoles bacia A mérica. La inmigración en masa, Alianza Editorial, Madrid, 1988, pp. 322-342 (Sociedad Quinto Centenario).

—, "La inmigración española en México: un modelo cualitativo" en Alicia Hernández Chávez y Manuel Miño Grijalva (coords.), Cincuenta años de bistoria en México, COLMEx, México, 1991, t. 1, pp. 201-215.

(comp.), Una inmigración privilegia-

da. Comerciantes, empresarios y profesionales españoles en México en los siglos XIX y XX, Alianza Editorial, México, 1994 (Alianza América, 34).

-Lorenzo, María Dolores, "Banqueros y empleados españoles en Puebla, Oaxaca y Chiapas. El Banco Oriental de México, 1900-1915", tesis de maestría, UNAM, México, 2001.

-Ludlow, Leonor, "La primera etapa de formación bancaria (1864-1897)" en Leonor Ludlow y Jorge Silva Riquer (comps.), Los negocios y las ganancias de la colonia al México maderno, Instituto Mora/IIH-UnAM, México, 1993, pp. 330-359.

, "Empresarios y banqueros: entre el porfiriato y la revolución" en Clara Lida (comp.), Una inmigración privilegiada. Comeriantes empresarios y profesionales españoles en México en los siglos XIX y XX, Alianza Editorial, México, 1994, pp. 142-169 (Alianza América, 34).

- y Alicia Salmerón, La emisión de papel moneda en México, SHCP, México, 1997.

-Ludlow Leonor y Carlos Marichal (eds.), Banca y poder en México (1800-1925), Grijalbo, México, 1985 (Enlace/Historia).

-Manero, Antonio, La revolución bancaria en México, Banco Mexicano Somex/Miguel Ángel Porrúa, México, 1991. 
-Marichal, Carlos, "De la banca privada a la gran banca. Antonio Basagoiti en México y España, 1880-1911", Historia Mexicana, vol. XLVIII, núm. 4 (192), 1999, México, pp. 767-793.

- Memoria de las instituciones de crédito, correspondientes a los años de 1897, 1898, 1899, Tipografía de la Oficina Impresora del Timbre/ Palacio Nacional, México, 1900, t. I.

-Memoria de Hacienda y Crédito Público correspondiente al año económico del 1 de julio de 1901 a 30 de julio de 1902, Tipografía Impresora del Timbre, México, 1905, vol. I.

-Núñez de la Peña, Francisco, "Un Banco que vino del centro: una crónica (1884-1914)" en Leonor Ludlow y Carlos Marichal (eds.), Banca y poder en México (1800-1925), Grijalbo, México, 1985, pp. 209-225 (Enlace/Historia).

-Pérez Herrero, Pedro, “Algunas hipótesis de trabajo sobre la inmigración española México: los comerciantes" en Clara E. Lida (coord.), Tres aspectos de la presencia española en México durante el porfiriato, Colmex, México, 1979, pp. 103 173.

-Primera asamblea general ordinaria, celebrada el 18 de abril de 1913. Informe del Consejo de Administración y del comisario, Imprenta Modernista, Puebla, 1913.

-Sharp, Jim, "Historia desde abajo" en Peter Burke (ed.), Formas de bacer historia, Alianza, Madrid, 1993, pp. 38-58 (Alianza Universidad, 765).

-Tortella, Gabriel, El desarrollo de la España contemporánea. Historia económica de los siglos XIX y XX, Alianza Editorial, Madrid, 1998.

-Valdaliso, Jesús Ma. y Santiago López, Historia económica de la empresa, Crítica, Barcelona, 2000 (Nuevos Instrumentos Universitarios). 